\title{
Selective photothermolysis of spider veins and reticular varices with the long-pulsed Nd:YAG laser
}

\section{Selektive Photothermolyse der Besenreiser und retikulären Varizen mit dem langgepulsten Nd:YAG-Laser}

Authors

A. A. M. Fratila' , G. G. Gauglitz², A. Strohbücker ${ }^{1}$, D. Radu ${ }^{3}$

Affiliations

1 Jungbrunnen-Klinik GmbH, Bonn

2 Klinik and Poliklinik für Dermatologie and Allergologie, Ludwig-Maximilians-Universität München

3 Clinica 1 Chirurgie, Universitatea de Medicina si Farmacie Victor Babes, Timisoara, Romania

Key words

spider veins, telangiectasia, reticular veins, long pulsed (LP) $\mathrm{Nd}$ :YAG laser, photosclerosis

Schlüsselwörter

Besenreiser, Teleangiektasien, retikuläre Varizen,

langgepulster (LP) Nd:YAG-Laser, Photosklerose

received 28.06.2018

accepted 16.01.2019

\author{
Bibliography \\ DOI https://doi.org/10.1055/a-0865-5296 \\ Phlebologie 2020; 49: 16-21 \\ (c) Georg Thieme Verlag KG, Stuttgart · New York \\ ISSN 0939-978X
}

Correspondence

Prof. Dr.-medic (RO) Alina Fratila

alina.fratila@jungbrunnenklinik.de

\section{ABSTRACT}

The therapy of spider veins, telangiectasia and reticular veins of lower extremities can be successfully performed with sclerotherapy or by using the long pulsed (LP) Nd:YAG laser. A matter of discussion, however, is how should laser parameters - such as wavelength, fluence, pulse duration, number of pulses - be utilized for effective and selective photothermolysis treatment without any side effects. The selective photothermolysis was introduced in 1983 by Anderson and Parrish [1] as a concept in laser treatment, meaning the selective thermal destruction of the target tissue (the chromophores - the light-absorption molecule is here the blood vessel) using a specific laser light wavelength, with minimal injury to surrounding tissue (the skin). The effectiveness of the selective photothermolysis process using an LP Nd:YAG laser at $1064 \mathrm{~nm}$ for the treatment of leg veins telangiectasias up to $2 \mathrm{~mm}$ in diameter, is the result of 30 -years clinical experience sustained by patient satisfaction and photo documentation. The use of double and triple pulses seems to be the key of success in treating even larger vessels and has demonstrated superior safety and efficacy. Even bigger telangiectasias, reticular veins or other dilated veins on neckline, upper abdomen or in the face can be successfully treated with the LP Nd:YAG laser.

\section{ZUSAMMENFASSUNG}

Die Behandlung von Besenreisern, Teleangiektasien und retikulären Varizen der unteren Extremitäten kann erfolgreich entweder mit der Sklerotherapie erfolgen oder durch Einsatz des langgepulsten (LP) Nd:YAG-Lasers. Gegenstand der Diskussion ist, wie die Lasereinstellungen zu erfolgen haben - also die Wellenlänge, die Energiedensität, die Puls-Länge und die PulsZahl - für eine effektive selektive Photothermolyse-Behandlung möglichst ohne jegliche Nebenwirkungen. Die selektive Photothermolyse, ein Begriff, der 1983 von Anderson und Parrish etabliert wurde [1], ist ein physikalisches Wirkprinzip, das in der Lasertherapie die gezielte thermische Zerstörung einer bestimmten Gewebestruktur (auch Ziel-Chromophor genannt - hier Blutgefäße) mithilfe einer spezifischen Wellenlänge bedeutet, ohne die umliegenden Gewebe (hier Haut) zu beschädigen. Die Effektivität der selektiven Photothermolyse für die Behandlung von Besenreisern und retikulären Varizen bis zu 2 mm im Durchmesser unter Anwendung eines LP-Nd: YAG-Lasers mit einer Wellenlänge von $1064 \mathrm{~nm}$ ist Ergebnis einer 30-jährigen Erfahrung, gestützt sowohl auf die geäußerte Zufriedenheit der Patienten als auch unterstützt durch Photodokumentation. Die Anwendung von Doppel- bzw. 3-Fachpulsen scheint der Schlüssel bei der Behandlung auch von größeren Gefäßen zu sein und hat sich als hochgradig sicher und wirkungsvoll erwiesen. Auch größere Teleangiektasien, retikuläre Varizen bzw. allgemein Venektasien im Bereich von Dekolleté, Oberbauch oder auch im Gesicht können erfolgreich mit dem LP-Nd:YAG-Laser behandelt werden. 


\section{Introduction}

Telangiectasias, known colloquially as spider veins, and reticular veins are more common in women (about $40 \%$ ) than men (about $15 \%)$. They are primarily an aesthetic problem, but they also have underlying genetic and hormonal factors. Standing for long periods at work may also be a reason for the development of spider veins. Overweight is another reason [2,3]. Even when the patient presents to the doctor mainly for aesthetic reasons, there should be a thorough examination of the venous system to rule out any underlying incompetence of trunk or perforating veins [4].

\section{Anatomical considerations}

Reticular veins are small blue varicose veins within the skin that usually measure less than $3 \mathrm{~mm}$ in diameter [5]. Spider veins or telangiectasias, which may be dark red or dark blue in colour, also lie within the skin but are smaller, with a diameter of $0.2-$ $2 \mathrm{~mm}$, and tend to be more superficial. They have the appearance of a spider's web or a starburst. The very small telangiectasias lie immediately below the surface of the skin and are therefore ideally suited to laser therapy. These dilated vessels, whether red or blue or very fine or somewhat coarser, are the main reason for the patient to visit a phlebologist and may also be present even when there is no venous insufficiency [6]. If valve incompetence in the trunk vein is diagnosed on investigation, it is recommended that the larger veins are treated first, either with endovenous thermal ablation (radiofrequency or laser) or high saphenofemoral ligation and stripping in more advanced cases. The reticular veins and spider veins are then dealt with, either by means of sclerotherapy or an LP Nd:YAG laser [7]. Sclerotherapy is a good method for treating dilated veins, which is both effective and cost-effective, as has been demonstrated in numerous studies [3].

\section{Long-pulsed (LP) Nd:YAG laser}

Various Laser and Intense Pulsed Light (IPL) devices have been tested in the treatment of telangiectasias of the legs over the last 30 years (long-pulsed Alexandrite laser, long-pulsed dye laser, KTP laser, diode laser, IPL). The results with the laser devices first used were not at all satisfactory or only moderately so $[8,9]$. These comparative studies showed that the LP Nd:YAG laser was much more effective than diode lasers $(810 \mathrm{~nm})$ and Alexandrite lasers (755 nm). Numerous studies [10-14] have confirmed that the LP $\mathrm{Nd}$ :YAG laser with 3-100 ms pulses is a very efficient and safe method of treatment for telangiectasias measuring $0.2-3 \mathrm{~mm}$ in diameter [6]. When treating blood vessels with laser light, the three most important chromophores (light-absorbing molecules) are haemoglobin in the blood and melanin and water in the skin. When a specific laser wavelength is absorbed by a chromophore, all the energy is transmitted to the target chromophore. Light of different wavelengths is absorbed by different target chromophores. In the case of blood vessels, the target chromophore is haemoglobin. Ideally, the wavelength selected should be one that is absorbed exclusively by haemoglobin and not by other chromophores such as water or melanin. This is the case with the
LP Nd:YAG laser and its $1064 \mathrm{~nm}$ wavelength. In order to destroy the vessel, sufficient heat must be absorbed (sufficient fluence). In addition, a sufficiently long duration of exposure (pulse duration = the time for which the vessel is heated) is necessary to allow the selective heating and slow coagulation of the vessel, without damaging the surrounding structures. These properties of optimal wavelength, sufficient fluence and pulse duration represent the cornerstones of the theory of selective photothermolysis. The low absorption of LP Nd:YAG laser by melanin means that the laser beam is not absorbed by the epidermis, but penetrates deeper layers, with the result that dark pigmented skin can also be treated. Although the absorption of the LP Nd:YAG laser $(1064 \mathrm{~nm})$ in haemoglobin is relatively weak compared to a dye laser $(585 \mathrm{~nm})$, it is still ten times higher than the absorption in water, the main chromophore in the dermis (15). Since absorption in the blood is relatively low, there must be a very high energy density (fluence), and this is possible because the absorption by melanin is even lower. The effects of the LP Nd:YAG laser change some the haemoglobin molecules into methaemoglobin (MetHb) $[16,17]$. The leg veins that are located deeper contain more deoxyhaemoglobin $(\mathrm{Hb})$ than oxyhaemoglobin $\left(\mathrm{HbO}_{2}\right)$ [17]. The absorption coefficient of the $1064 \mathrm{~nm}$ wavelength is about 20 times higher in MetHb than in $\mathrm{Hb}$. The conversion into MetHb begins a few milliseconds after the first laser shot and it is therefore very important to send double and triple pulses, in order to utilise the thermal effects of the second and third pulses to the maximum. In addition, the total energy delivery is much higher than that achieved with a single pulse. Treatment with the LP Nd: YAG causes photothermal damage to the vessel wall through absorption into the haemoglobin and subsequent photosclerosis (sclerosis with laser light= photon) [18]. The combined use of long and multiple pulses allows the vessel to be heated slowly and evenly without burning the skin as well as causing a sub-purpuric reaction without haematoma formation and intravascular coagulation [6, 19]. During the laser process, the haemoglobin chromophores change as follows: $\mathrm{HbO}_{2}$ becomes $\mathrm{Hb}$ as a result of coagulation and denaturation, which in turn becomes MetHb as a result of oxidation and denaturation of the cell membranes [8] ( Fig. 1).

The treatment of reticular veins and spider veins should also follow the sequence of largest to smallest vessel. In this way, the incompetent perforating veins - referred to as feeder veins - are treated first. We recommend using a larger laser spot diameter ( $\geq 6 \mathrm{~mm}$ ). In addition, the advantage is that larger spots do not have a large scatter and the higher laser energy reaches the desired target in the deeper layers. The choice of pulse time is also very important for effective treatment. The longer action of pulse times greater than $10 \mathrm{~ms}$ has an optimal collagen shrinking effect, resulting in better occlusion of the vessel. Slow heating of the vessel seems to be the most important mechanism for permanent occlusion. Conforming to selective photothermolysis, the ideal pulse is long enough to cause thermal coagulation of the endothelium with minimal perivascular side effects $[6,14,19]$.

In summary, the LP Nd:YAG laser presents an optimal solution for treating telangiectasias on the legs for the following reasons: it has an optimal wavelength, absorption in the target chromophore (vessel) is good, it sufficiently penetrates skin to reach the target 


\begin{tabular}{|c|c|c|c|c|c|}
\hline \multicolumn{3}{|c|}{$\begin{array}{l}\text { Retikuläre Varizen größer als } \\
2 \mathrm{~mm} \text {, tiefergelegen, dunkelblau }\end{array}$} & \multicolumn{2}{|c|}{$\begin{array}{c}\text { Retikuläre Varizen } \\
\text { kleiner als } 2 \mathrm{~mm} \text {, } \\
\text { dunkelrot }\end{array}$} & \multirow[t]{2}{*}{$\begin{array}{c}\text { Besenreiser kleiner } \\
\text { als } 0,5 \mathrm{~mm} \text {, reich in } \\
\mathrm{HbO}_{2}\end{array}$} \\
\hline $7 \mathrm{~ms}$ & $7 \mathrm{~ms}$ & $6 \mathrm{~ms}$ & 8-11ms & $7-8 \mathrm{~ms}$ & \\
\hline & \multicolumn{2}{|c|}{$25 \mathrm{~ms}$} & \multicolumn{2}{|c|}{$25 \mathrm{~ms}$} & \\
\hline \multicolumn{3}{|c|}{ Energiedensität } & \multicolumn{2}{|c|}{ Energiedensität } & Energiedensität \\
\hline \multicolumn{3}{|c|}{$140-150 \mathrm{~J} / \mathrm{cm}^{2}$} & \multicolumn{2}{|c|}{$140-150 \mathrm{~J} / \mathrm{cm}^{2}$} & $120-130 \mathrm{~J} / \mathrm{cm}^{2}$ \\
\hline \multicolumn{3}{|c|}{ Mit moderater Kompression } & \multicolumn{2}{|c|}{ Mit leichter Kompression } & Ohne Kompression \\
\hline
\end{tabular}

- Fig. 1 Treatment of reticular veins of different sizes.
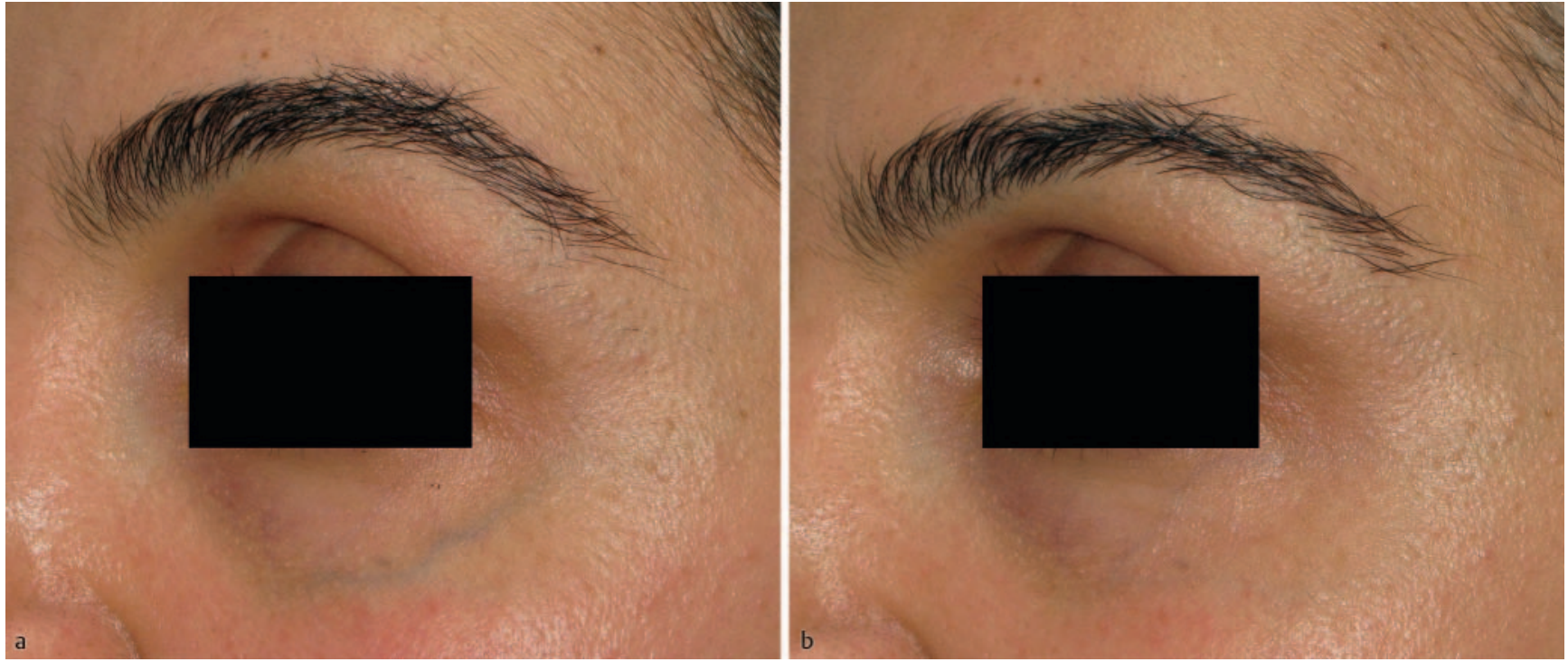

Fig. 2 a Infraorbital telangiectasia before treatment. b Three months after Nd:YAG laser therapy.

vessels (small perforating veins can also be treated effectively), it has the greatest effect out of all types of lasers thanks to its minimal absorption in the epidermis and lowest absorption by melanin - which means that post-inflammatory hyperpigmentation (PIH) is extremely rare. The three pulse sequences with their different delay times provide dynamic cooling of the epidermis (without substantially cooling the dermis), so that sufficient fluence and pulse duration are achieved in the target tissues to allow selective heating and slow coagulation of the target vessel and its intima, without causing any damage to the surrounding tissues (the skin). The pulse duration should correspond to the thermal relaxation time of the target structure (shorter or the same length). The thermal relaxation time is the time that the target tissues require to pass the absorbed heat on to the surrounding structures.
Larger telangiectasias, reticular veins or general venous ectasia in the cleavage, on the upper abdomen or even on the face can be successfully treated with the LP Nd:YAG laser ( $\triangleright$ Fig. 2).

\section{LP Nd:YAG treatment}

Although a few patients find the LP Nd:YAG laser to be painful, most people tolerate the treatment well and even tolerate a higher number of laser pulses without complaint. A few testshots are recommended to ascertain the patient's sensitivity to pain. Administering an oral analgesic about 30 minutes prior to treatment or applying a local anaesthetic gel without vasoconstricting effects about 15 minutes beforehand may help [7]. Immediately before treatment, the anaesthetic gel should be carefully removed and the skin degreased. A cooled transparent ultrasound 

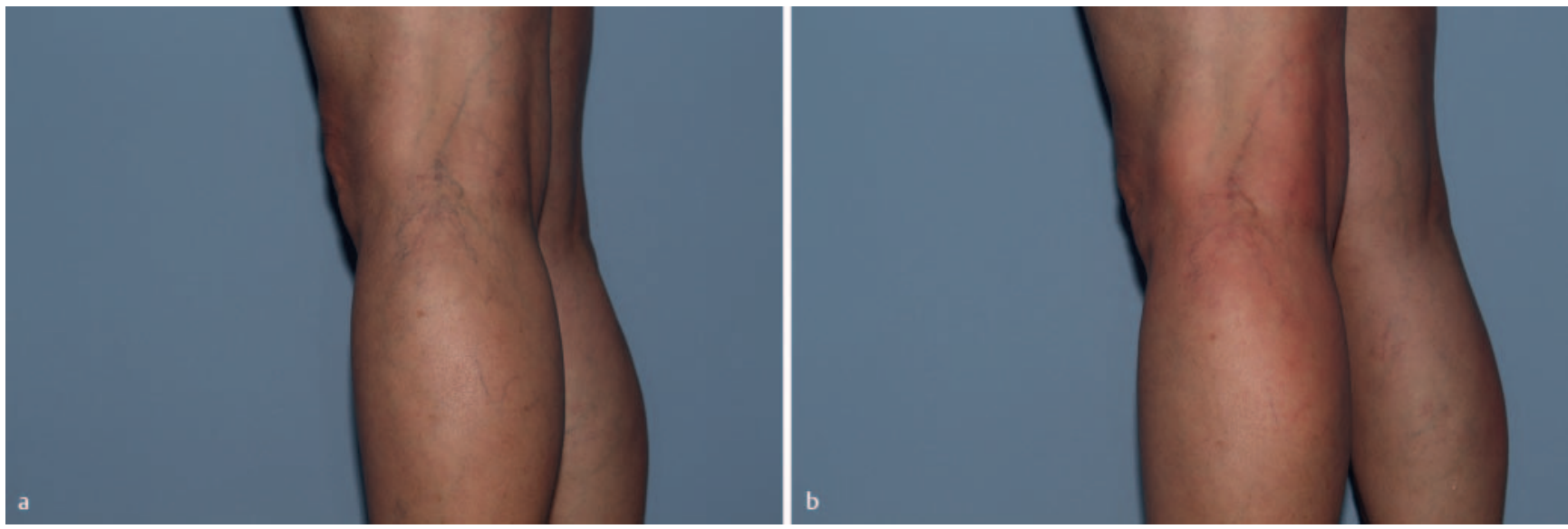

- Fig. 3 a Reticular veins in the popliteal fossa before laser therapy. b Typical clinical reactions immediately after treatment with the LP Nd:YAG laser: vasospasm, erythema, oedema.

gel is then applied to the area to be treated. If the gel becomes milky during treatment, the laser head and the skin should be cleaned. New gel is then applied [7].

There are four lightguides that can be attached to the LP Nd: YAG laser handpiece: round with diameters of $1.5 \mathrm{~mm}, 6 \mathrm{~mm}$, and $9 \mathrm{~mm}$ and a rectangular guide measuring $2 \times 4 \mathrm{~mm}$ [7]. The treating physician must first select the spot size depending on the size of the vessel to be treated: a smaller spot for fine superficial veins and larger spots for thicker and more deeply lying veins. Several recommendations for use are stored in the system of our LP Nd:YAG laser, which are very helpful for the beginner [7]. We start with the larger deeper reticular veins and use a triple pulse with pulse times of $7 \mathrm{~ms}$ and corresponding delays of $25 \mathrm{~ms}$ : $7 \mathrm{~ms}-25 \mathrm{~ms}-7 \mathrm{~ms}-25 \mathrm{~ms}-6 \mathrm{~ms}$ - Fig. 1). The selected fluence is $140-150 \mathrm{~J} / \mathrm{cm}^{2}$. Telangiectasias that are smaller than $2 \mathrm{~mm}$ in diameter and from dark red to purple in colour, are treated with a double pulse: $8-11 \mathrm{~ms}$ for the first pulse and $7-8 \mathrm{~ms}$ for the second, with a delay of $25 \mathrm{~ms}$ and the same fluence of 140$150 \mathrm{~J} / \mathrm{cm}^{2}$. Finally, we treat the very fine spider veins of less than $0.5 \mathrm{~mm}$ in diameter, which are bright red and rich in $\mathrm{HbO}_{2}$. The present article presents a treatment method that is always carried out with the Nd:YAG laser handpiece of the M22 multiapplication device from Lumenis ${ }^{\circledR}$. The treatment parameters given in this article are to be considered as recommendations only and must not be extrapolated to other Nd:YAG lasers. In general, treatment with the LP Nd:YAG laser depends less on the technical affinity than on the selected settings and the treatment skills of the doctor. After each applied shot, the treated vessel should be massaged with the highly cooled lightguide, to massage away the intravascular coagulum and render any later removal of haematoma unnecessary [7]. Before the start of treatment, the area to be treated should be cooled by a back-and-forth movement of the cooled laser head for 1-2 seconds. This massage in the preparatory phase allows the direction of blood flow to be determined. Before using the LP Nd:YAG laser, the position of the laser head is orientated to the direction of blood flow, in order to squeeze the blood away. To ensure a good contact, the laser head is positioned obliquely against the skin and slight to moderate pressure is ap- plied. The exerted contact pressure is proportional to the size and depth of the vein, in order to reduce the overall diameter of the vein and maintain a good density of action. The effects of the heat are diminished by the reduction in blood volume. As a result, the treatment will of course be less painful, especially in the case of the largest veins, and will thereby also prevent the formation of large intravascular haematomas. If the blood return flow is slow, the direction of the lightguide is not so important. Irrespective of the spot size, closure of thinner blood vessels is less painful than it is for larger vessels. Positioning of the LP Nd:YAG lightguide at an oblique angle and treating the entire length of the blood vessel can also reduce the likelihood of the lumen reopening. It goes without saying that heavily tanned skin and skin treated with self-tanning agents should not be treated. Slightly hyperpigmented skin can be treated and we are therefore prepared to treat these patients throughout the summer as well. It is then recommended to reduce the fluence by about $10 \%$ to $15 \%$ and to use only double or triple pulse therapy, whereby the interval between the pulses should be increased to $30 \mathrm{~ms}$.

There are several clinical reactions that indicate successful treatment: the immediate disappearance of blood from the vessel, a dark colour to the blood, which indicates coagulation and should be massaged away immediately with the lightguide, and delayed erythema and oedema ( $>$ Fig. 3 ) or purpura-like maculae. Even if there is no immediate reaction to be seen, the same area should not be treated again straight away with a second pulse sequence, but several seconds should be allowed before re-lasering. This prevents blistering. If a soft popping noise is heard, it is a sign that extreme localised heating may have led to the vessel bursting. This area must be checked at the end of treatment or a few days afterwards and, if necessary, the vessel must be removed to eliminate any microthrombi. This helps to prevent any postinflammatory hyperpigmentation (PIH). Cooling the skin immediately after treatment is very important and restricts the leakage of haemosiderin. Furthermore, we recommend the application of a cortisone cream, which should be continued for 2-3 days after treatment. If, unlike expected, a large haematoma develops, heparin cream or gel may help, but we do not prescribe this 


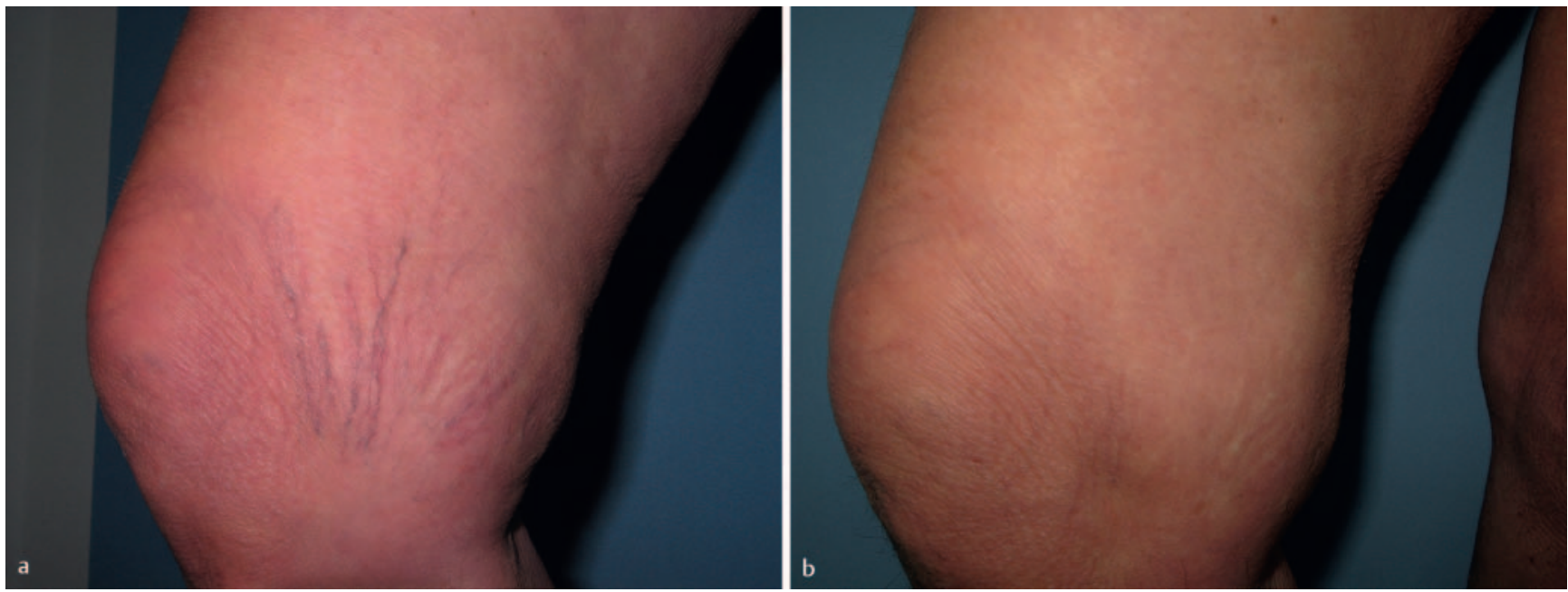

- Fig. 4 a Reticular veins and spider veins on the inner aspect of the distal thigh, before laser therapy. $\mathbf{b}$ After three sessions of LP Nd:YAG laser therapy.
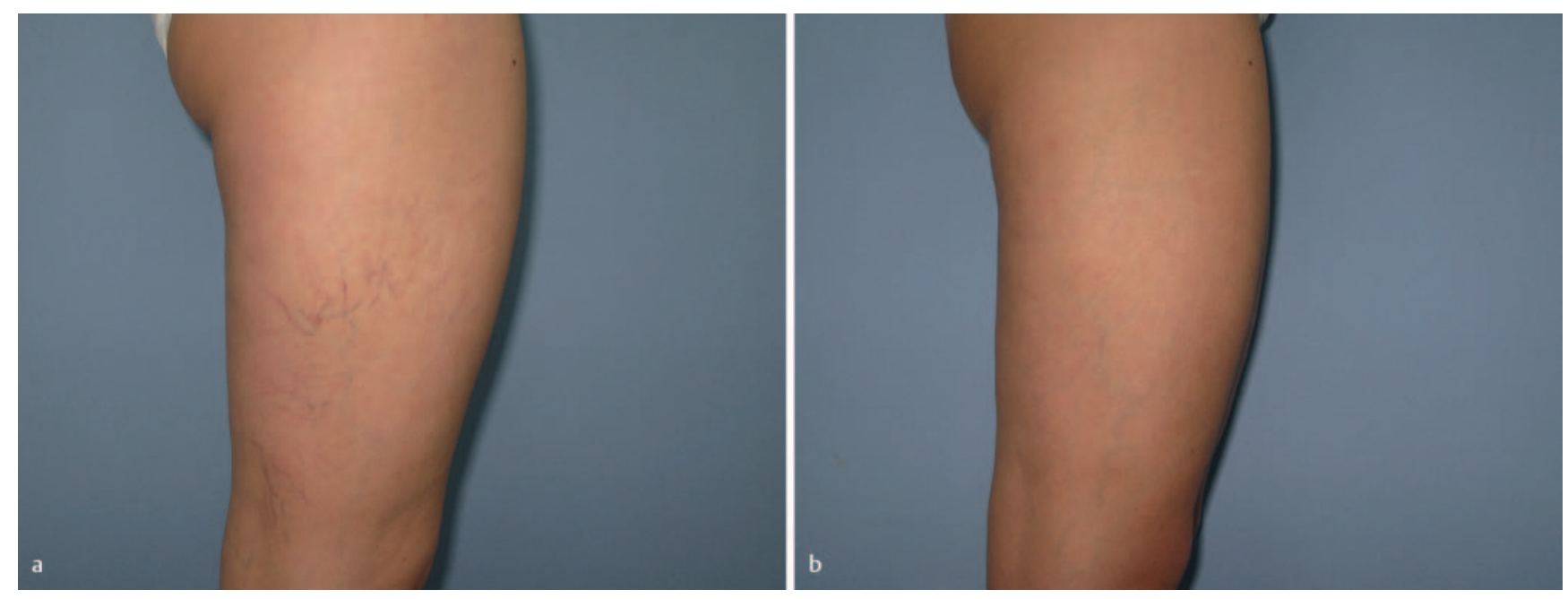

- Fig. 5 a Spider veins on the outer aspect of the thigh, before laser therapy. $\mathbf{b}$ After 4 sessions of LP Nd:YAG laser therapy at 2-3 monthly intervals. The picture was taken more than 8 months after the last treatment session.
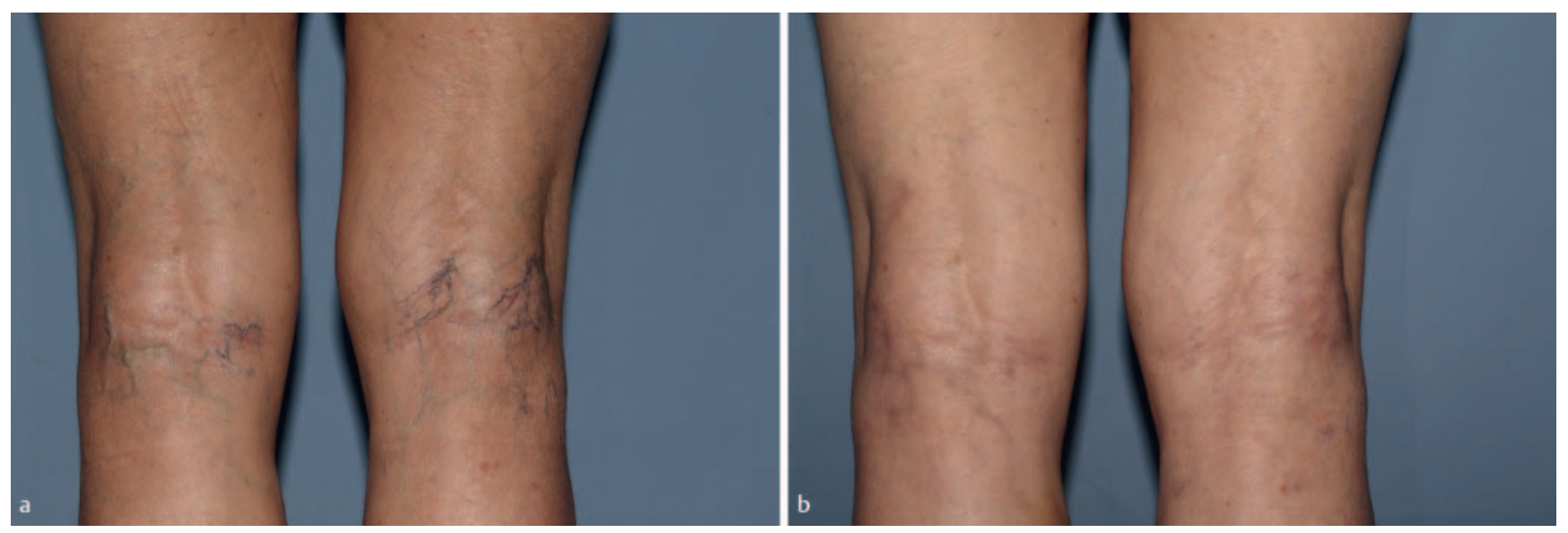

- Fig. 6 a Reticular veins and spider veins in the popliteal fossa of both legs, before treatment. Foam sclerotherapy was performed only on the right side, the day the picture was taken. $\mathbf{b}$ Three months after the second session with LP Nd:YAG laser therapy of the popliteal fossa of both legs. 
routinely. Subsequent treatment sessions should be planned at intervals of 6-8 weeks ( $\triangleright$ Fig. 4-6). Patients must be told to avoid any excessive exposure to the sun until the next treatment session and not to use any self-tanning agents before then. Sunscreen should be used consistently during holidays [7].

\section{Advantages of treating reticular veins and spider veins with the LP Nd:YAG laser}

There are no allergic reactions either during or after laser treatment. Pain is minimised with the use of a local anaesthetic gel or oral analgesics. So far, thrombosis has not been observed as a side effect, so there is no limit to the number of veins or areas that can be treated. All reticular veins and spider veins can be treated in one session, providing the patient's pain tolerance allows it. Reticular veins on the foot, below the medial or lateral malleolus, can also be treated without the risk of a deep vein thrombosis. Hypopigmentation and hyperpigmentation are extremely rare with correct use of the laser. However, a very long learning curve for the user is normal. Compression bandages are not necessary. Wearing compression stockings is also not really necessary, but we do recommend that class I compression stockings are worn for 1-2 weeks, if larger reticular veins have been treated [7]. Busy people particularly appreciate the laser method, because they only need to come for treatment every two months - with a total of 3-5 sessions on average. Combination with IPL is possible and advisable when there is matting, as our laser devices are appropriately equipped for such use.

For patients, who are set on having laser therapy, this is their main reason for seeking out your practice.

\section{Summary}

The LP Nd:YAG with its $1064 \mathrm{~nm}$ wavelength allows the deepest penetration of all non-invasive vascular lasers. The high energy allows penetration into the dermis and also the destruction of large vessels. The LP Nd:YAG with larger spots penetrates deeper. The multiple pulses also penetrate deeper and allow greater thermal relaxation times. The long pulse duration leads to a slower and more uniform heating of the vessel, without causing it to burst thus reducing the possibility of later purpura and hyperpigmentation.

\section{Conflict of interest}

The first two authors are key opinion leaders of Lumenis ${ }^{\circledR}$. They receive honoraria from this company for presentations made at weekend workshops. They have not received any fee for the present article.

\section{References}

[1] Anderson RR, Parrish JA. Selective photothermolysis: precise microsurgery by selective absorption of pulse radiation. Science 1983; 220 : 524-727

[2] Parlar B, Blazek C, Cazzaniga S et al. Treatment of lower extremity telangiectasias in women by foam sclerotherapy vs. Nd:YAG laser: a prospective, comparative, randomized, open-label trial. JEADV 2014

[3] Lohr JM, Bush RL. Venous disease in women: Epidemiology, manifestations, and treatment. J Vasc Surg 2013; 57: 37-45

[4] Munia MA, Wolosker N, Munia CG et al. Comparison of laser versus sclerotherapy in the treatment of lower extremity teleangiectases: a prospective study. Dermatol Surg 2012; 38: 635-639

[5] Meissner MH. Lower extremity venous anatomy. Semin Intervent Radiol 2005; 22 (3): 147-156

[6] Ross EV, Domankevitz Y. laser Treatment of Leg Veins: Physical Mechanisms and Theoretical Considerations lasers Surg. Med 2005; 36: 105116

[7] Lumenis ${ }^{\circledR}$, Wittig C. Leg veins - Long-pulsed (LP) Nd:YAG Guidelines/ CD-1008960 Rev A 2017.

[8] Gloviczki P, Comerota A], Dalsing MC et al. Society for Vascular Surgery; American Venous Forum. The care of patients with varicose veins and associated chronic venous diseases: Clinical practice guidelines of the Society for Vascular Surgery and the American Venous Forum. J Vasc Surg 2011; 53: 2-48

[9] Eremia S, Li C, Umar SH. A side-by-side comparative study of $1064 \mathrm{~nm}$ $\mathrm{Nd}: Y A G, 810 \mathrm{~nm}$ diode and $755 \mathrm{~nm}$ alexandrite lasers for treatment of $0.3-3 \mathrm{~mm}$ leg veins. Dermatologic Surgery 2002; 28 (3): 224-230

[10] Dover JS, Sadick NS, Goldman MP. The role of laser $s$ and light sources in the treatment of leg veins. Dermatol Surg 1999; 25: 328-335

[11] Adamic M, Troilius A, Adatto M et al. Vascular laser s and IPLS: Guidelines for care from the European Society for Laser Dermatology. J Cosmet Laser Ther 2007; 9: 113-124

[12] Sadick NS, Weiss RA, Goldman MP. Advances in laser surgery for leg veins: Bimodal wavelength approach to lower extremity vessels, new cooling techniques and longer pulse durations. Dermatol Surg 2002; 28: $16-20$

[13] Levy JL, Elbahr C, Jouve E et al. Comparison and sequential study of long pulsed Nd:YAG 1,064 nm laser and sclerotherapy in leg telangiectasias treatment. Lasers in Surgery and Medicine 2004; 34: 273-276

[14] Trelles MA, Allones I, Martín-Vázquez MJ et al. Long pulse Nd:YAG laser for treatment of leg veins in 40 Patients with assessments at 6 and 12 months. Lasers in Surgery and Medicine 2004; 35: 68-76

[15] Bäumler W, Ulrich H, Hartl A et al. Optimal parameters for the treatment of leg veins using Nd:YAG lasers at $1064 \mathrm{~nm}$. British Journal of Dermatology 2006; 155: pp364-pp371

[16] Randeberg LL, Bonesrønning JH, Dalaker M et al. Methaemoglobin formation during laser-induced photothermolysis of vascular skin lesions. Lasers Surg Med 2004; 34: 414-419

[17] Black JF, Barton JK. Chemical and structural changes in blood undergoing laser photocoagulation. Photochemistry and Photobiology 2004; 80: 89-97

[18] Mordon S, Brisot D, Fournier N. Using a "non uniform pulse sequence" can improve selective coagulation with a Nd:YAG laser $(1.06 \mathrm{~mm})$ thanks to Met-hemoglobin absorption: a clinical study on blue leg veins. Lasers in Surgery and Medicine 2003; 32: 160-170

[19] Parlette EC, Groff WF, Kinshella MJ et al. Optimal pulse durations for the treatment of legtelangiectasias with a Neodymium YAG laser. Lasers in Surgery and Medicine 2006; 38: 98-105 